\title{
Molecular Bases of $\beta$-Thalassemia in the Eastern Province of Saudi Arabia
}

\author{
Amein K. Al-Ali, ${ }^{1}$ Suad Al-Ateeq, ${ }^{1}$ Burhan W. Imamwerdi, ${ }^{2}$ Saleh Al-Sowayan, ${ }^{3}$ \\ Mohammed Al-Madan, ${ }^{4}$ Fahad Al-Muhanna, ${ }^{5}$ Laila Bashaweri, ${ }^{3}$ and Foad Qaw ${ }^{1}$ \\ ${ }^{1}$ Department of Biochemistry, College of Medicine, King Faisal University, PO Box 2114, Dammam 31451, Saudi Arabia \\ ${ }^{2}$ Department of Medical Laboratory Technology, College of Medicine, King Faisal University, Dammam 31451, Saudi Arabia \\ ${ }^{3}$ Department of Pathology, College of Medicine, King Faisal University, Dammam 31451, Saudi Arabia \\ ${ }^{4}$ Department of Pediatrics, College of Medicine, King Faisal University, Dammam 31451, Saudi Arabia \\ ${ }^{5}$ Department of Internal Medicine, College of Medicine, King Faisal University, Dammam 31451, Saudi Arabia
}

Received 26 January 2005; revised 1 June 2005; accepted 9 June 2005

\begin{abstract}
$\beta$-thalassemia is a group of heterogeneous recessive disorders common in many parts of the world. Al-Qatif and Al-Hassa oases in the Eastern Province of Saudi Arabia are regions known for high frequency of these disorders. Using two molecular methods, based on multiplexing-amplification refractory system and reverse hybridization principles, the spectrum of $\beta$-thalassemia in the region was studied. Sixty-nine subjects with known $\beta$-thalassemia disease and volunteers with high hemoglobin $\mathrm{A}_{2}\left(\mathrm{HbA}_{2}\right)$ and low mean corpuscular volume (MCV) were included in this study. Ten mutations were detected in $91 \%$ of the subjects under study. Six of these mutations had previously been observed while the other four mutations are reported here for the first time. In addition, four of the mutations accounted for $76.8 \%$ of the subjects studied. IVSII-1 ( $\mathrm{G}>\mathrm{A}$ ), IVSI-5 (G > A), and codon 39 (C >T) mutations were found to be the most frequent. However, the frequencies of different mutations reported here are slightly different from those reported earlier. A number of these mutations were also found in the neighboring countries, which can be explained in terms of gene flow.
\end{abstract}

\section{INTRODUCTION}

$\beta$-thalassemia is a group of heterogeneous autosomal recessive disorders due to the absence or reduced synthesis of the $\beta$-globin chain [1]. Consequently, the excess production of $\alpha$-globin chain leads to its precipitation within the red blood cells causing ineffective erythropoiesis $[2,3]$. Extensive work in the last two decades has led to the elucidation of the spectrum of these monogenic disorders [4]. Over 200 different mutations leading to $\beta$ thalassemia have been characterized worldwide [3]. A varied clinical expression is exhibited by homozygotes and compound heterozygotes [5]. The majority of these mutations are due to small nucleotide substitutions and deletions [3]. However, the mutations are population specific,

Correspondence and reprint requests to Amein K. Al-Ali, Department of Biochemistry, College of Medicine, King Faisal University, PO Box 2114, Dammam 31451, Saudi Arabia, E-mail: ameinali@hotmail.com

This is an open access article distributed under the Creative Commons Attribution License which permits unrestricted use, distribution, and reproduction in any medium, provided the original work is properly cited. and common and rare mutations are found in each population [6]. In the Middle East codon 39 (C > T), IVSI-110 $(\mathrm{G}>\mathrm{A})$, IVSI-1 $(\mathrm{G}>\mathrm{A})$, IVSI-6 $(\mathrm{T}>\mathrm{C})$, IVSII-1 $(\mathrm{G}>$ A), codon 5(-CT), and IVSI-5 (G >C) mutations account for more that $90 \%$ of $\beta$-thalassemia mutations in the region $[7,8]$. However, these mutations differ in numbers and frequencies between different populations of the Middle East. Over fifty different mutations have been identified in the Arab populations reflecting the heterogeneity of these populations. In order to prevent transmission of the mutation, carriers of $\beta$-thalassemia need to be identified since their offspring are at risk of inheriting the mutation. Therefore, this work was carried out to study the spectrum of mutations of $\beta$-thalassemia in the Eastern Province of Saudi Arabia where inherited blood disorders are common.

\section{METHODS}

Over a period of two years, sixty-nine blood samples were randomly collected from unrelated Saudi male and female individuals with $\beta$-thalassemia attending King $\mathrm{Fa}$ had Hospital of the University, Al-Khobar, and from volunteers with $\mathrm{HbA}_{2}>3 \%$ (50 volunteers, 19 patients). After written informed consent was obtained, $3 \mathrm{~mL}$ of whole 
TABLE 1. $\beta$-thalassemia alleles identified in the population of the Eastern Province of Saudi Arabia.

\begin{tabular}{lccc}
\hline Mutation & Mutation class & Origin & Allele frequency $(\%)$ \\
\hline IVSII-1 $(\mathrm{G}>\mathrm{A})$ & Splice site & Mediterranean & 27.5 \\
IVSI-5 $(\mathrm{G}>\mathrm{C})$ & Consensus mutation & Asian & 23.2 \\
Codon $39(\mathrm{C}>\mathrm{T})$ & Nonsense & Mediterranean & 20.3 \\
IVSI-1 $(\mathrm{G}>\mathrm{A})$ & Splice junction & Mediterranean & 5.8 \\
IVSI-6 $(\mathrm{T}>\mathrm{C})$ & Consensus splice site & Mediterranean & 4.4 \\
IVSI-25 bp & Splice junction & Asian & 4.4 \\
Codon $5(-\mathrm{CT})$ & Frameshift & Mediterranean & 1.5 \\
Codon 36/37 $(-\mathrm{T})$ & Frameshift & Kurdish/Iranian & 1.5 \\
Codon $44-\mathrm{C}$ & Frameshift & Kurdish & 1.5 \\
IVSII-745 $(\mathrm{C}>\mathrm{G})$ & Consensus splice site & Mediterranean & 1.5 \\
\hline
\end{tabular}

blood was collected in EDTA-coated tubes. Complete blood count was determined using Coulter Micro Diff II machine and $\mathrm{HbA}_{2}$ was determined by affinity chromatography. Genomic DNA was extracted from peripheral blood leukocytes according to standard procedures [9]. Mutation detection was carried out by the method of Fortina et al, which is based on the combination of multiplexing and amplification refractory system [10]. Five common mutations were screened by four separate reactions containing upstream primer and either four normal or four mutant primers. Polymerase chain reaction (PCR) mixtures contained $1 \mu \mathrm{g}$ of genomic DNA, $100 \mathrm{mM}$ Tris $\mathrm{HCl}(\mathrm{pH} 8.3), 50 \mathrm{mM} \mathrm{KCl}, 100 \mu \mathrm{M}$ dNTP mixture, $1.5 \mathrm{mM} \mathrm{MgCl}_{2}$, and $0.01 \%(\mathrm{w} / \mathrm{v})$ gelatin in a total volume of $50 \mu \mathrm{L}$. The mixtures were heated for 5 minutes at $95^{\circ} \mathrm{C}$ followed by the addition of four units of Taq DNA polymerase. Twenty-five PCR cycles of $95^{\circ} \mathrm{C}$ for 1 minute and combined annealing and extension at $66^{\circ} \mathrm{C}$ for 2 minutes with the last cycle of 3 minutes at $66^{\circ} \mathrm{C}$ were carried out. The $\beta$ - globin strip $\mathrm{A}^{\text {assay }}$ kit was used to confirm the results obtained by the multiplex PCR method as well as detecting those mutations not covered by the above method [11]. In this method, PCR amplification was carried out using biotinylated primers, followed by hybridization of the PCR product to a test strip containing allele-specific oligonucleotide probes immobilized as an array of parallel lines. Bound biotinylated sequences were detected using streptavidin phosphatase and color substrate.

\section{RESULTS AND DISCUSSION}

$\beta$-thalassemias are severe congenital disorders caused by mutations in the $\beta$-globin gene resulting in the absence or reduced synthesis of the $\beta$-globin chain. This deficit leads to precipitation of excess $\alpha$-globin chains resulting in the formation of inclusion bodies. In homozygotes and compound heterozygotes, this leads to a life-long dependency on blood transfusions to maintain satisfactory levels of hemoglobin along with iron chelation therapy to combat iron overload. Gene frequency for thalassemia differs markedly among different populations, reaching $10 \%$ in certain areas. Over 200 different mutations have been elucidated worldwide. However, in each population a number of common mutations (usually about 5-10) exist which account for more than $90 \%$ of all mutations [12]. $\beta$-thalassemia is endemic in the Arab countries including the countries of the Gulf region [8]. In Al-Qatif and Al-Hassa oases in the Eastern Province of Saudi Arabia, the frequency of hemoglobin $S$ and both $\beta$ and $\alpha$-thalassemia has been reported to be high $[13,14]$. A number of reports have described the type of mutations that are common among the population of this area $[15,16,17]$. However, in the present study we report additional mutations which have not been reported earlier due to either limited sample size or the limitations of the procedures used. Ninety percent of all samples included in this study which had high $\mathrm{HbA}_{2}(>3 \%)$ and low MCV $(<70 \mathrm{ft})$ were shown to be homozygous or heterozygous for one of the $\beta$-thalassemia mutations detected by our procedures. Ten mutations were identified in all subjects studied (Table 1). Six of these mutations (IVSII-1 $(\mathrm{G}>\mathrm{A})$, codon 39 (C > T), IVSI-5 (G > C), IVSI-25 bp, IVSI-1 (G $>A)$, and codon $44(-\mathrm{C})$ ) have previously been identified in the Eastern Province population [15, 16, 17]. Four of the mutations (codon 5 (-CT), IVSII-745 ( $\mathrm{G}>\mathrm{C}$ ), IVSI$6(\mathrm{~T}>\mathrm{A})$, and codon $36 / 37(-\mathrm{T})$ ) are reported here for the first time in this population. Four of the mutations account for $76.8 \%$ of subjects studied. IVSII-1 (G > A) mutation was the most frequently encountered with a frequency of $27.5 \%$. This was followed by IVSI-5 ( $\mathrm{G}>\mathrm{C}$ ) with a frequency of $23.2 \%$, codon $39(\mathrm{C}>\mathrm{T})$ with a frequency of $20.3 \%$, and IVSI-1 ( $\mathrm{G}>\mathrm{A}$ ) with a frequency of $5.8 \%$. All other detected mutations had a genotype frequency of $4.4 \%$ or less.

Most of these mutations are found in neighboring countries with varying frequency. This is in line with studies in other parts of the world which have shown that gene flow due to population migration is common. Although IVSII-1 $(G>A)$ has been previously reported to have an allele frequency of $15.1 \%$, our study indicates that in fact it is the most common mutation (27.5\%) in this area [17]. This mutation is also the most common in neighboring Kuwait at a frequency of $29 \%$ [18]. Codon 39 (C > T) which is found in western Mediterranean countries and in 
neighboring Bahrain (24\%) has been reported previously in the Saudi population at a high frequency $[17,18,19]$. Interestingly, the IVSI-5 ( $\mathrm{G}>\mathrm{C}$ ) mutation has been reported at a very low frequency of $1.8 \%$ for the Eastern Province population [17] and at a higher frequency of $12 \%$ for the country as whole [15], in comparison to $23.2 \%$ in the present study. Although it is difficult to speculate on these discrepancies, it is worth mentioning that this mutation is the most frequent and widespread in the neighboring regions. The frequency of IVSI-5 (G $>$ C) mutation in the Western Province of Saudi Arabia, Bahrain, Kuwait, UAE, and Oman are 22.5\%, 16.2\%, $18 \%, 55 \%$, and $62 \%$, respectively $[8,19,20,21]$. Therefore, it is not surprising that the IVSI-5 $(\mathrm{G}>\mathrm{C})$ mutation is found at high frequency in the Eastern Province due to gene flow. Both IVSI-1 ( $\mathrm{G}>\mathrm{A}$ ) and IVSI-6 (T > A), which are Mediterranean in origin, are also found at lower frequencies in the population of the Eastern Province. Although IVSI-25 bp mutation is found at high frequency in neighboring Bahrain (36\%), in the population of the Eastern Province it is only found at low frequency $(2.7 \%)$. Codon $44(-\mathrm{C})$ mutation, which is of Kurdish origin, is found in the Gulf country of Oman and at a low frequency in the present population of the Eastern Province. Codon $36 / 37(-\mathrm{T})$ which is of Kurdish/Iranian origin and IVSII745 ( $\mathrm{G}>\mathrm{C}$ ) and IVSI-6 ( $\mathrm{T}>\mathrm{A}$ ) which are of Mediterranean origin are also found in the present population but at a lower frequency. Therefore, it is not surprising that such mutations are found in the Eastern Province due to the close proximity of these populations.

In summary, the present report identifies four new mutations in the population of the Eastern Province. The frequencies of the mutations reported in the present study are in line with the frequencies of these mutations reported in the surrounding populations.

\section{ACKNOWLEDGMENT}

We would like to extend our gratitude to King Abdulaziz City for Science and Technology for funding this project.

\section{REFERENCES}

[1] Weatherall SJ, Clegg JB, eds. The Thalassemic Syndrome. Oxford, UK: Blackwell Science; 2001:550572.

[2] Steinber MH, Forget BG, Higgs DR, Nagel RL. Disorders of Hemoglobin: Genetics, Pathopysiology and Clinical Management. Cambridge, UK: Cambridge University Press; 2001.

[3] Weatherall SJ. The thalassaemias. In: Stamatoyannopoulos G, Nienhuis AW, Majerus PH, Varmus $\mathrm{H}$, eds. The Molecular Bases of Blood Diseases. 2nd ed. Philadelphia, Pa: W. B. Saunders; 1994:157-205.

[4] Huisman TH, Carver MF. The $\beta$ and $\alpha$-thalassemia repository. Hemoglobin. 1998;22(2):169-195.
[5] Weatherall DJ. Pathophysiology of thalassaemia. Baillieres Clin Haematol. 1998;11(1):127-146.

[6] Flint J, Harding RM, Boyce AJ, Clegg JB. The Population Genetics of the haemoglobinopathies. Baillieres Clin Haematol. 1998;11(1):1-51.

[7] Cao A, Gossens M, Pirastu M. $\beta$-thalassaemia mutations in Mediterranean populations. Br J Haematol. 1989;71(3):309-312.

[8] Zahed L. The spectrum of $\beta$-thalassaemia mutations in the Arab populations. J Biomed Biotechnol. 2001;1(3):129-132.

[9] Miller SA, Dykes DD, Polesky HF. A simple salting out procedure for extracting DNA from human nucleated cells. Nucleic Acids Res. 1988;16(3):12151216.

[10] Fortina P, Dotti G, Conant R, et al. Detection of the most common mutations causing $\beta$-thalassemia in Mediterraneans using a multiplex amplification refractory mutation system (MARMS). PCR Methods Appl. 1992;2(2):163-166.

[11] Maggio A, Giambona A, Cai SP, Wall J, Kan YW, Chehab FF. Rapid and simultaneous typing of hemoglobin S, hemoglobin C, and seven Mediterranean beta-thalassemia mutations by covalent reverse dot-blot analysis: application to prenatal diagnosis in Sicily. Blood.1993;81(1):239-242.

[12] Huisman TH. Frequencies of common betathalassaemia alleles among different populations: variability in clinical severity. $\mathrm{Br} J$ Haematol. 1990;75(4):454-457.

[13] Pembrey ME, Perrine RP, Wood WG, Weatherall DJ. Sickle beta 0 thalassemia in the Eastern Saudi Arabia. Am J Hum Genet. 1980;32(1):26-41.

[14] El-Hazmi MA, Warsy AS. Appraisal of sickle-cell and thalassaemia genes in Saudi Arabia. East Mediterr Health J. 1999;5(6):1147-1153.

[15] El-Hazmi MA, Al-Swailem AR, Warsy AS. Molecular defects in beta-thalassaemias in the population of Saudi Arabia. Hum Hered.1995;45(5):278-285.

[16] Hasounah FH, Sejeny SA, Omer JA, Old JM, Oliver RW. Spectrum of beta-thalassaemia mutations in the population of Saudi Arabia. Hum Hered. 1995;45(4):231-234.

[17] El-Harth EH, Kuhnau W, Schmidtke J, Stuhrmann M, Nasserallah Z, Al-Shahiri A. Identification and clinical presentation of beta thalassaemia mutations in the eastern region of Saudi Arabia. J Med Genet. 1999;36(12):935-937.

[18] Adekile AD, Gu LH, Baysal E, et al. Molecular characterization of alpha-thalassemia determinants, beta-thalassemia alleles, and beta $S$ haplotypes among Kuwaiti Arabs. Acta Haematol. 1994;92(4):176-181.

[19] Jassim N, Merghoub T, Pascaud O, et al. Molecular basis of $\beta$-thalassemia in Bahrain: an epicenter for a Middle East specific mutation. Ann NY Acad Sci.1988;850:407-409. 
[20] Quaife R, Al-Gazali L, Abbes S, et al. The spectrum of $\beta$-thalassemia mutations in the UAE national population. J Med Genet. 1994;31(1):59-61.

[21] Daar S, Hussein HM, Merghoub T, Krishnamoorthy R. Spectrum of $\beta$-thalassemia mutations in Oman. Ann NY Acad Sci. 1998;850:404-406. 

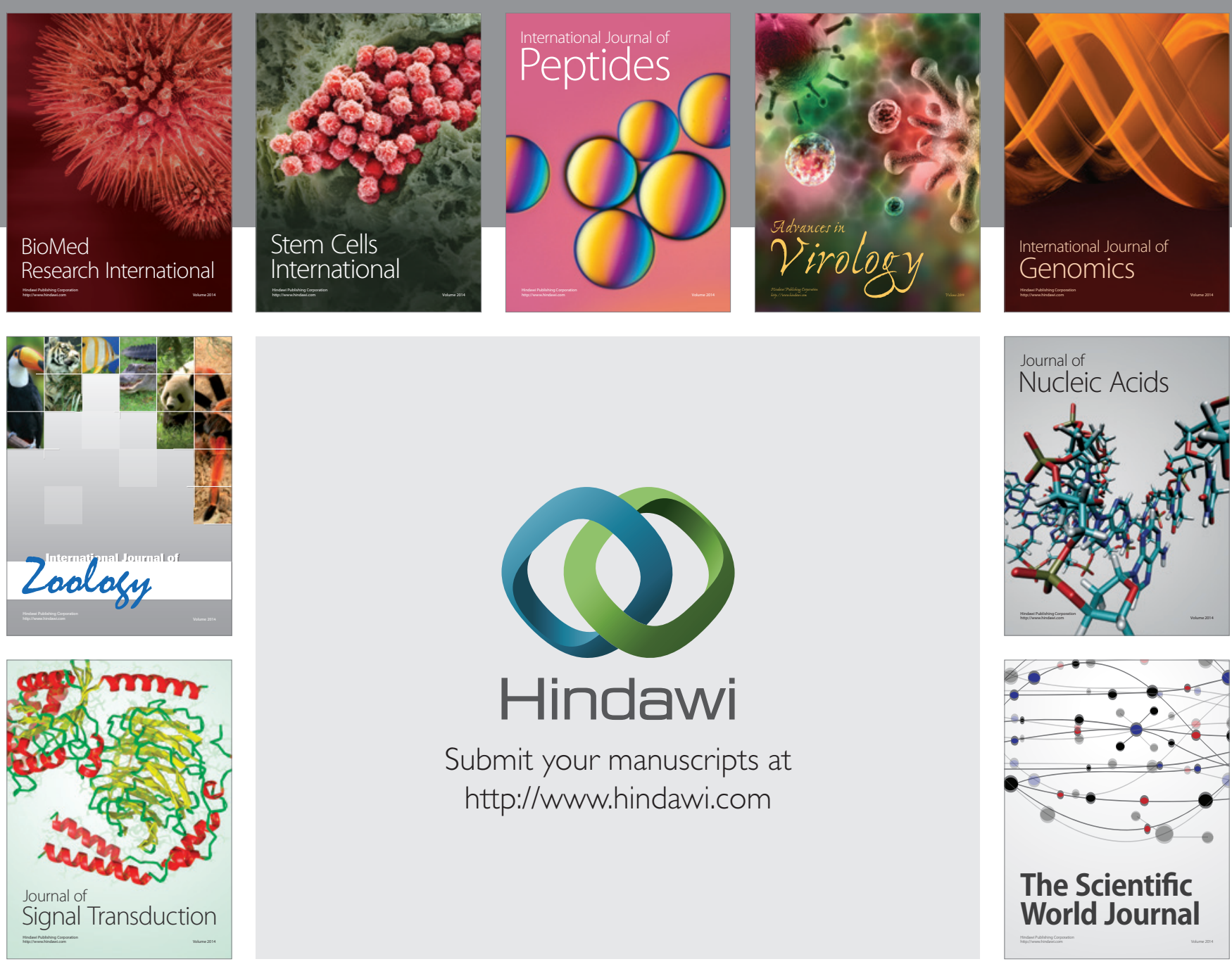

Submit your manuscripts at

http://www.hindawi.com
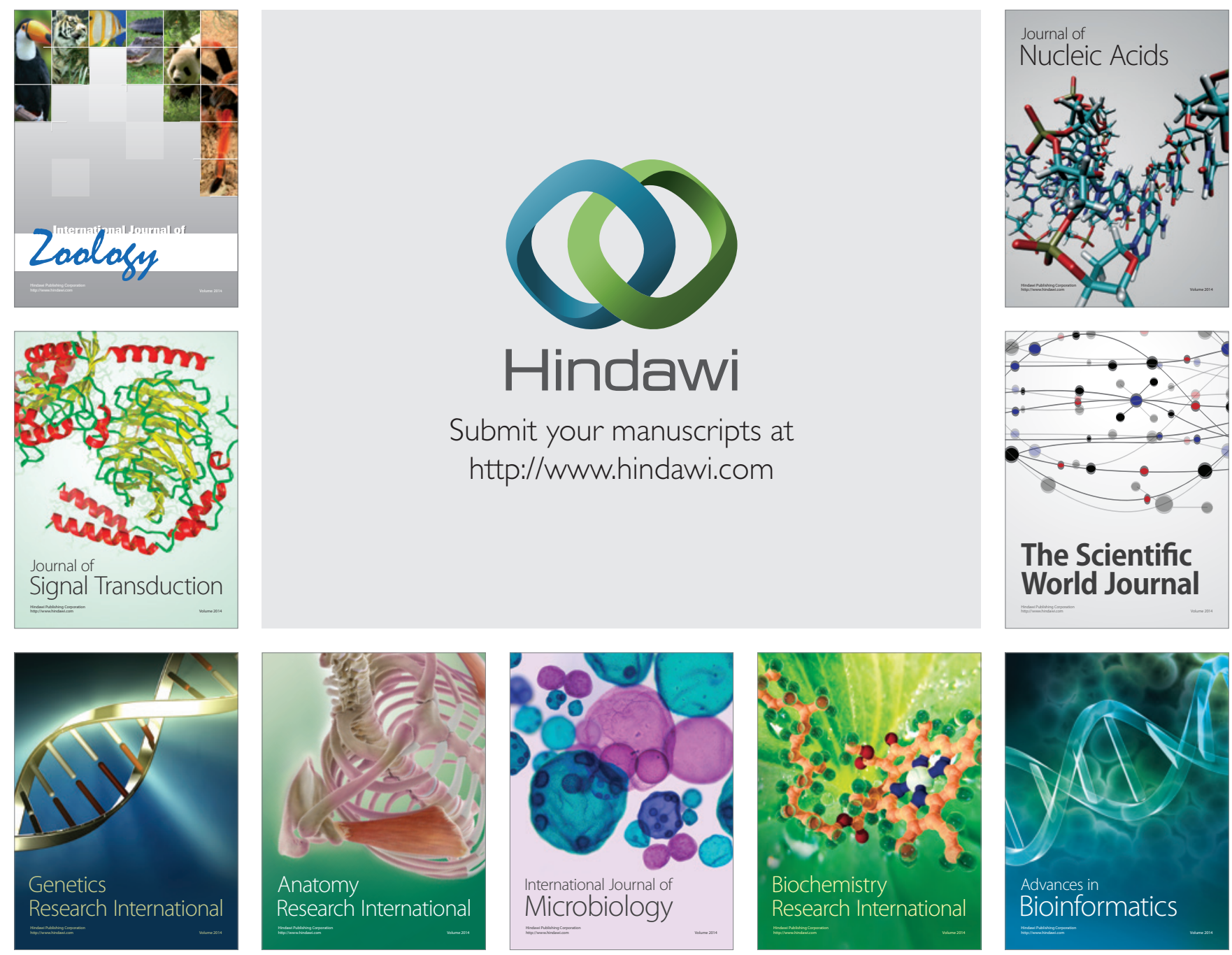

The Scientific World Journal
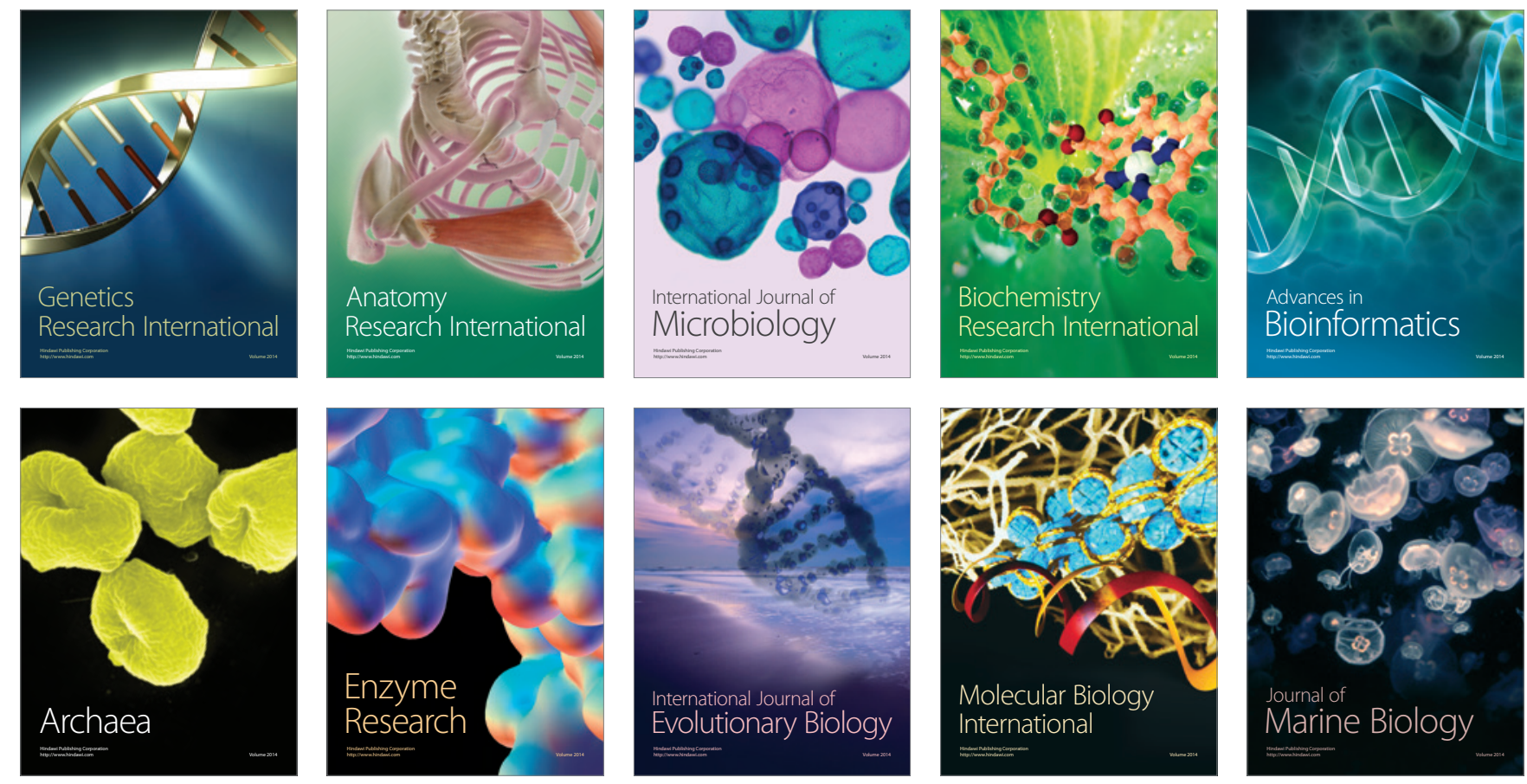